\title{
O ensino do telejornalismo nas universidades federais do Nordeste do Brasil em tempos de convergência digital
}

\author{
Paulo Eduardo Lins Cajazeira \\ Professor Adjunto da Universidade \\ Federal do Cariri (UFCA) no Programa \\ de Pós-Graduação em Biblioteconomia \\ e no Curso de Jornalismo. Doutor \\ em Comunicação e Semiótica pela \\ PUC-SP, pós-doutorado em Ciências \\ da Comunicação da Universidade \\ da Beira Interior (UBI), Portugal. \\ E-mail: paulo.cajazeira@ufca.edu.br
}

Resumo: O objetivo deste estudo é investigar as tecnologias digitais no ensino de telejornalismo em universidades federais da região Nordeste do Brasil. A pesquisa inicial focou-se no estudo do perfil dos docentes e das suas produções laboratoriais. No total foram pesquisadas doze universidades em nove estados brasileiros. A pergunta norteadora procurou verificar como as instituições de ensino acompanharam a mudança curricular com as novas Diretrizes Curriculares Nacionais de Jornalismo e os impactos da tecnologia digital no ensino do telejornalismo. Para tanto, entrevistamos um grupo fechado de professores universitários que lecionam essa unidade curricular e analisamos as matrizes curriculares e as produções audiovisuais acadêmicas a fim de compreender o processo de convergência digital pelo qual passa o ensino do telejornalismo.

Palavras-chave: Telejornalismo; Laboratório; Convergência; Mídias; Novas Diretrizes de Jornalismo; Tecnologias Digitais.

Newscasting teaching in federal universities of Northeast Brazil in times of digital convergence

Abstract: We aim to investigate digital technologies in newscasting teaching at federal universities in Northeast Brazil. The initial research focused on studying the profile of teachers and their laboratory productions, twelve universities were surveyed in nine Brazilian states. The guiding question sought to verify how educational institutions followed the curricular change by the National Curriculum Guidelines for Journalism and the impacts of digital technology in newscasting teaching. For this, we interviewed a closed group of university professors who teach this subject and analyzed academic matrices and academic audiovisual productions to understand the process of digital convergence in which newscasting is taught.

Keywords: Newscasting; Laboratory; Convergence; Media; New Curriculum for Journalism; Digital Technology. 


\section{Introdução}

Os cursos de jornalismo, assim como os demais cursos superiores no Brasil desde que foram criados, estão subordinados ao Estado no que se refere aos protocolos de autorização e reconhecimento, bem como às determinações do tempo de duração e constituição curricular. Somente em 2001 as Diretrizes Curriculares Nacionais (DCN) foram aprovadas e, assim, instituições de ensino tiveram ampla liberdade para compor suas estruturas curriculares conforme o perfil de egresso desejado e sem imposição por parte do Ministério da Educação (MEC) (BRASIL, 2013).

O curso de jornalismo foi criado em 1943, com a publicação do Decreto-Lei no 5.480 (BRASIL, 1943). Contudo, o primeiro curso, da Faculdade Cásper Líbero, foi implementado em 1947, conforme o Decreto no 22.245, de 1946, que instituiu

${ }^{1} \mathrm{~A}$ partir de então, outros três currículos foram aprovados pelo governo nos anos de 1948, 1949 e 1950, respectivamente. O currículo de 1946 privilegiou o jornalismo impresso, embora o rádio já estivesse presente no país desde a década de 1920 e, nos anos de 1930, já fosse comercial. O currículo de 1948 de certa forma corrigiu essa ausência com a disciplina Radiodifusão no 3ㅇ ano. O de 1949 contemplou três seções dos decretos no 23.087, de 19 de maio de 1947; no 24.719, de 29 de março de 1948; no 26.493, de 19 de março de 1949; no 28.923, de 1어 de dezembro de 1950 (BRASIL, 1947, 1948, 1949, 1950). E o de 1950 alterou a denominação da disciplina Radiodifusão para Radiojornalismo. Com a criação dos currículos mínimos pelo Ministério da Educação, o curso de jornalismo teve dois aprovados.

${ }^{2} \mathrm{O}$ currículo mínimo ampliou o número de disciplinas e as categorizou em gerais ou de cultura geral, especiais ou instrumentais e técnicas ou de especialização. Fato relevante que deve ser enfatizado é que, no ano de 1969, o curso de jornalismo passou a ser habilitação de um curso criado pelo MEC: o de Comunicação Social. Esse novo curso sofreu forte influência do Centro Internacional de Estudos Superiores de Periodismo para a América Latina (Ciespal), órgão mantido pela Organização das Nações Unidas para Educação, Ciência e Cultura (Unesco), com sede em Quito, Equador, que incentivava a figura do comunicador social. O curso de Comunicação Social contou com três currículos mínimos instituídos, o de 1969, outro em 1978 e o último no ano de 1984. No currículo mínimo de 1969, estava previsto o aprofundamento das técnicas de jornalismo impresso, radiofônico, televisado e cinematográfico. o currículo (BRASIL, 1946). ${ }^{1}$ O programa mínimo de $1962^{2}$ criou a disciplina técnica de Rádio e Telejornal, em atendimento às necessidades do jornalismo de televisão, ou seja, desde 1962 temos disciplina ligada ao estudo de jornalismo audiovisual. No currículo mínimo de 1978 foi incluído o projeto experimental, que deveria ser realizado no último semestre do curso e com laboratório disponível pela escola. No último currículo mínimo, em 1984, foram descritas as ementas de todas as disciplinas, assim como de todos os equipamentos necessários aos laboratórios de redação, planejamento gráfico, radiojornalismo, telejornalismo, jornalismo fotográfico, hemeroteca e jornal-laboratório.

A proposta de bacharelado em jornalismo foi debatida muito antes de as diretrizes serem promulgadas, tendo sido oficializada em seminário ocorrido na Pontifícia Universidade Católica de Campinas, organizado e copromovido pela Federação Nacional dos Jornalistas, pelo Fórum de Professores de Jornalismo, pelo Observatório da Imprensa e pelo grupo de trabalho de Jornalismo da Sociedade Brasileira de Estudos Interdisciplinares da Comunicação (Intercom). No seminário de Campinas, foi reconhecida como válida e legítima a possibilidade de existência de cursos superiores de jornalismo sem a necessidade de serem constituídos como habilitação do curso de Comunicação Social. Entretanto, as diretrizes de 2001 mantiveram a habilitação em jornalismo, e foi somente no ano de 2013 que, finalmente, se transformou em bacharelado em jornalismo, com as aprovações do Parecer CNE/CES n 39, de 20 de fevereiro de 2013, e da Resolução no 1, de 27 de setembro de 2013 (BRASIL, 2013a, 2013b).

No ano de 2013, foram publicados o parecer e a resolução que criaram as Diretrizes Curriculares Nacionais em Jornalismo. Mas é relevante salientar que o relatório que as propôs foi elaborado no ano de 2009 por uma comissão de especialistas e demorou quatro anos para ser aprovado no Conselho Nacional de Educação, a presidência dessa comissão ficou a cargo do professor José Marques de Melo. A comissão indicou que o curso deve ser estruturado com conteúdos que atendam a seis eixos de formação: fundamentação humanística, fundamentação específica, fundamentação contextual, formação profissional, aplicação processual e prática laboratorial.

Aprovado o Parecer CNE/CES no 39, alguns meses mais tarde foi aprovada a Resolução no 1, de 2013, que instituiu as DCN para o curso de graduação em jornalismo, bacharelado. A referida resolução deu prazo máximo de dois anos a partir da data de sua publicação, para que as instituições de educação superior, obrigatoriamente, implantassem as diretrizes. É justamente a partir da obrigatoriedade de implantação dos novos projetos pedagógicos dos cursos de jornalismo que nos atentaremos aos reflexos das mídias digitais no ensino laboratorial. A importância do órgão laboratorial está principalmente em não apenas fazer, mas refletir sobre o fazer. Essa reflexão e crítica sobre a prática profissionalizante contribuem para a articulação entre teoria e prática desenvolvida nos órgãos laboratoriais (LOPES, 1989). 


\section{O ensino laboratorial em tempos de convergência digital}

Um laboratório, conceitualmente falando, define-se como local que garante a oportunidade para experimentação, observação ou prática para cientistas, alquimistas ou jornalistas (BRASIL, 2012). Segundo o professor Antonio Brasil (2012: 10), "se a principal e mais significativa característica ou promessa do meio televisivo é mostrar a realidade ao vivo, como ensinar jornalismo em televisão sem uma televisão?". Em cenário de mudanças curriculares dos cursos de jornalismo, um dos principais objetivos deveria ser a qualificação docente e de equipamentos para conhecer e avaliar o potencial das novas tecnologias, linguagens ou narrativas audiovisuais (BRASIL, 2012). As novas DCN tensionam o ambiente de formação para que se permita, em seus novos movimentos, maior amplitude, com práticas pedagógicas que reflitam os fins educativos que se pretendem com a educação, relacionando-se, portanto, com o currículo, ou seja, com o tipo de profissional que se pretende construir.

No eixo de prática laboratorial das novas DCN, mencionam-se projetos editoriais que devem ser elaborados, definidos e orientados a públicos reais, com publicação efetiva e periodicidade regular, tais como: jornal, revista e livro, jornal mural, radiojornal, telejornal, webjornal, agência de notícias, assessoria de imprensa, entre outros. Porém, para que essa produção realmente se concretize satisfatoriamente, é preciso que as instituições de ensino disponham de condições laboratoriais adequadas, com espaços e equipamentos de qualidade e em quantidade. Os conteúdos voltados às práticas laboratoriais são os que precisam ser constantemente revisitados com vistas à experimentação. De acordo com o exarado, as práticas laboratoriais desenvolvem conhecimentos e habilidades inerentes à profissão a partir da aplicação de informações e valores (ANTONIOLI, 2014).

Os desafios da inovação curricular encontram-se justamente nessa articulação entre fundamentos curriculares e caráter pedagógico na ação docente, pois, segundo Libâneo (2000), é nesse ponto, em que a teoria se une à prática, que o trabalho docente é produzido, sendo que o comprometimento do professor é fundamental, pois é nesse momento que a produção pedagógica acontece. Estar consciente dos objetivos educacionais refletirá em sua postura diante do objeto de conhecimento e em sua relação com a prática pedagógica, de maneira a lembrar-lhe que o que define uma prática como pedagógica é o rumo que se dá às práticas educativas.

Contudo, para que ocorra concretização do currículo, ele precisa relacionar-se com o pedagógico. Políticas de formação e inovação curricular devem preocuparse, especialmente, com a passagem desse currículo às instituições de ensino, ao professor, ao currículo voltado para a ação, de forma que as orientações curriculares não estejam configuradas como meros discursos distantes e desconexos em que a inovação e a mudança tornem-se, tão somente, em palavras de efeito, discursos ecoando no imaginário pedagógico. É com essa reflexão que procuramos orientar nossa pesquisa à verificação dos efeitos das novas DCN nas práticas de ensino teórico-prático do telejornalismo.

O uso de tecnologias digitais provoca transformações nas maneiras de se perceber as realidades local e global e intervém cada vez mais na vida produtiva e nas formas de sociabilidade. Desse modo, a mídia constitui-se cada vez mais em ambiente estratégico de mediação de discursos de instituições e de outros campos de produção simbólica na contemporaneidade. Pensar e fazer televisão e telejornalismo no século XXI implica compreender que se vivencia a terceira fase de transmissões de notícias no Brasil e no mundo. $O$ rádio e o telégrafo sem fio caracterizaram a primeira fase. A segunda foi marcada pela transmissão de áudios e vídeos de grandes acontecimentos para todo o planeta via satélite e por cabo, culminando com a multiplicação de canais de notícias 24 horas (BECKER, 2015). 
Ao refletir sobre o ensino laboratorial do telejornalismo com o uso de novas mídias digitais e com a adaptação e incorporação de disciplinas ao universo on-line e a teorias que envolvem o ambiente web, é necessário rediscutir o currículo e as práticas pedagógicas das instituições aqui pesquisadas frente ao cenário que se apresenta: um mercado em constante transformação, que vem exigindo um profissional mais consciente do seu papel em um mundo cada vez mais conectado e que vai encontrar ambiente de trabalho de multiplataformas (DIAS; DALLA COSTA, 2015).

Conforme a professora Beatriz Becker (2015), no século XXI a emergência das tecnologias digitais também tem provocado novas formas de se perceber e relatar experiências e acontecimentos, atribuindo sentidos aos objetos, às pessoas, às comunidades étnicas e religiosas, às relações e às organizações. Testemunha-se a introdução de novos instrumentos e mídias para escrever e reescrever a história cotidiana. Ainda que a hibridização de linguagens e a interatividade não sejam características exclusivas da era digital, os tempos atuais indicam que muitas convenções que habitavam o mundo da escrita estão mais fluidas nas telas da TV e do computador e, de certo modo, sente-se mais liberdade para (re)imaginar a qualidade da relação que se estabelecerá com a escrita e os modos como serão usadas as tecnologias digitais (CLAYTON, 2013).

A avaliação do problema de pesquisa, nesse contexto, remete-nos a decifrar, mais uma vez, o uso de tecnologias digitais que reflitam a preocupação com as atividades laboratoriais do ensino do telejornalismo imerso numa cultura digital: Em que medida o uso das mídias digitais de informação e comunicação no ensino do jornalismo em $T V$ possibilita ao estudante compreender um universo tecnológico, digital, virtual, que exige novas habilidades do profissional da comunicação? Nesse contexto, as notícias, por meio das interações entre a TV e o computador, permitem consumo de conteúdos mais seletivo, on demand, e expansão da televisão em múltiplas plataformas, como celulares, jogos, iPods, iPads e serviços on-line -incluindo o YouTube. (BECKER, 2015).

\section{Metodologia e resultados preliminares}

A pesquisa teve início com o levantamento de dados sobre as universidades públicas federais do Nordeste que possuem curso de jornalismo. Nessa busca, os principais dados necessários foram relacionados ao telejornalismo e ao uso das novas mídias digitais. A partir dessa averiguação, foi criado um arquivo com os principais dados: nomenclatura da disciplina, carga horária, nome do(a) coordenador(a) do curso, site da universidade, site próprio do curso, vagas por curso e endereço eletrônico das produções laboratoriais.

Esse contato realizado para obtenção de dados das universidades foi feito por formulário eletrônico direcionado às instituições - mais especificamente aos coordenadores dos cursos. $O$ trabalho da pesquisa tornou-se mais difícil a partir do momento em que alguns dos coordenadores não responderam aos e-mails enviados ou à plataforma eletrônica solicitada para a coleta de dados. Dessa forma, após a dificuldade em se obter resposta de alguns coordenadores, tendo em vista a necessidade de prosseguir com a pesquisa, entramos em contato telefônico com algumas coordenações, além de termos utilizado de plataformas digitais: site da instituição, site do curso e páginas no Facebook.

Como parte da metodologia de pesquisa, criou-se um mapa com todas as informações obtidas nos questionários enviados aos coordenadores de curso. Assim, como no ofício de cartógrafo, desenvolveu-se material cartográfico com esses dados para compreensão das distâncias entre os cursos de jornalismo. Isso facilitou visão mais científica da pesquisa, retratada em números e estatísticas. Para análise, utilizou-se método comparativo para a diferenciação das particularidades de todas as instituições de ensino. A seguir, o mapa da região Nordeste do Brasil com indicação da localização dos cursos de jornalismo das universidades federais e do número de vagas. 


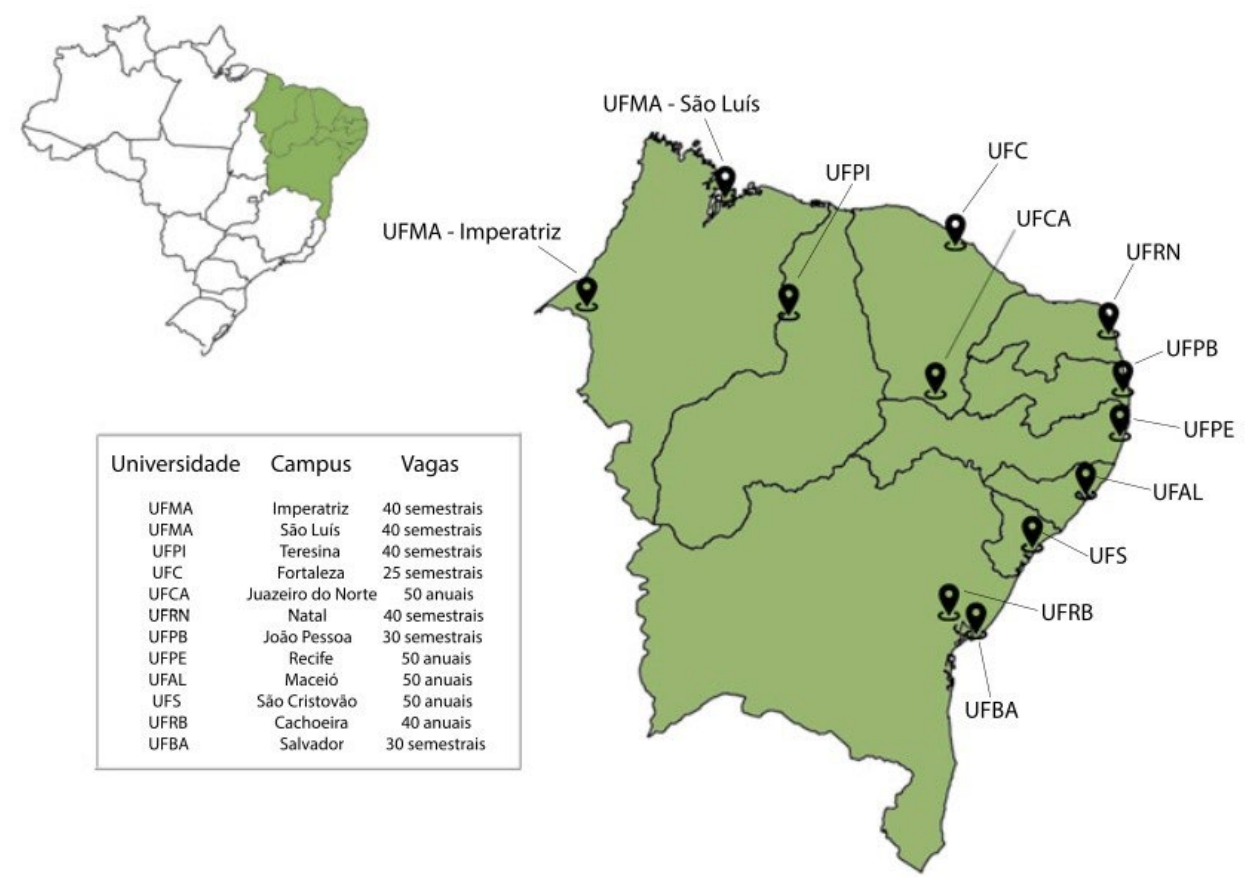

Figura 1: Mapa da região Nordeste com indicação da localização dos cursos de jornalismo das Universidades Federais Brasileiras

O curso de Comunicação Social da Universidade Federal do Maranhão (UFMA) foi criado em 1970 e teve seu currículo baseado no da Universidade de São Paulo (USP). Quando concebido, o vestibular era a única via de acesso e eram oferecidas vinte vagas por semestre (dois vestibulares por ano) com apenas duas habilitações: Jornalismo e Relações Públicas. Por causa da Resolução no 11/1969 do então Conselho Federal de Ensino (CEF), todos começavam juntos e a opção por uma ou outra habilitação só era possível a partir do quinto período - esse currículo vigorou até 1984. Atualmente, o campus de São Luís da UFMA conta com quarenta vagas semestrais, já o campus Imperatriz, com curso criado em 2006, completou dez anos de fundação e conta, também, com quarenta vagas semestrais.

Na Universidade Federal do Piauí (UFPI), campus de Teresina, o curso de jornalismo é de 1984 e são oferecidas quarenta vagas semestrais. O curso de Comunicação Social da Universidade Federal do Ceará (UFC) foi criado em 1965, com 25 vagas semestrais na área de jornalismo. No estado do Ceará também se encontra a Universidade Federal do Cariri (UFCA), em Juazeiro do Norte, que possui curso de jornalismo em funcionamento desde 2010, atualmente são oferecidas cinquenta vagas anuais. Fundado em 1962, o curso de jornalismo da Universidade Federal do Rio Grande do Norte (UFRN) é considerado um dos mais antigos da região Nordeste e oferece quarenta vagas semestrais. $O$ curso de Comunicação Social da Universidade Federal da Paraíba (UFPB), criado em 1977, possui duas habilitações: Jornalismo e Relações Públicas, conforme a Resolução no 24/1977, de 24 de março de 1977, do Conselho Superior de Ensino, Pesquisa e Extensão da UFPB. O Departamento de Jornalismo da UFPB conta com trinta vagas semestrais. $O$ curso de jornalismo da Universidade Federal de Pernambuco (UFPE) foi criado em 1984, em substituição ao antigo polivalente criado nos anos 1970; são oferecidas cinquenta vagas anuais.

Na Universidade Federal de Alagoas (Ufal), campus de Maceió, o curso de jornalismo tem seus precedentes na criação do curso de Comunicação Social, em 1978, com cinquenta vagas anuais. O curso de Jornalismo da Universidade Federal de Sergipe (UFS) funciona desde 1993, com cinquenta vagas anuais. $\mathrm{Na}$ Bahia, o curso de jornalismo é oferecido pela Universidade Federal do Recôncavo da Bahia (UFRB), em Cachoeira, desde 2006, com cinquenta vagas anuais; e pela Universidade Federal da Bahia (UFBA), em Salvador, em funcionamento desde 
1950, que tem o curso de jornalismo mais antigo das universidades federais da região Nordeste, com trinta vagas semestrais.

Após essa descrição podemos verificar que não há similaridade em datas de fundação dos cursos de jornalismo nas universidades federais do Nordeste. Tais datas acompanham a própria fundação das instituições, seu desenvolvimento e a evolução da Comunicação Social e do Jornalismo no país.

\begin{tabular}{|l|c|c|c|c|c|}
\hline & 1950 & 1960 & 1970 & 1980 & $1990-2010$ \\
\hline Total de cursos & 1 & 2 & 3 & 2 & 4 \\
\hline
\end{tabular}

Tabela 1: Cursos de Jornalismo de universidades federais com turmas abertas de 1950 a 2010 na região Nordeste do Brasil, por década de início do curso

\begin{tabular}{|l|c|c|c|c|c|c|c|c|c|c|}
\hline \multirow{2}{*}{} & \multicolumn{2}{|c|}{ Até 1970} & \multicolumn{2}{c|}{1980} & \multicolumn{2}{c|}{1990} & \multicolumn{2}{c|}{2000} & \multicolumn{2}{c|}{2010} \\
\cline { 2 - 13 } & $\mathbf{N}$ & $\%$ & $\mathbf{N}$ & $\%$ & $\mathbf{N}$ & $\%$ & $\mathbf{N}$ & $\%$ & $\mathbf{N}$ & $\%$ \\
\hline Sudeste & 8 & 44,44 & 29 & $\mathbf{5 6 , 8 6}$ & 31 & 51,67 & 77 & 56,62 & 144 & 45,57 \\
\hline Sul & 4 & 22,22 & 7 & 13,73 & 11 & 18,33 & 32 & 23,53 & 59 & 18,67 \\
\hline Nordeste & 6 & 16,67 & 8 & 13,73 & 10 & 16,67 & 15 & 11,03 & 58 & 18,35 \\
\hline Centro-Oeste & 2 & 11,11 & 4 & 7,84 & 4 & 6,67 & 8 & 5,88 & 33 & 10,44 \\
\hline Total de cursos & 18 & & 51 & & 60 & & 136 & & 316 & \\
\hline
\end{tabular}

Tabela 2: Distribuição regional dos cursos de jornalismo de universidade públicas e privadas com turmas abertas de 1940 a 2010 no Brasil, por década de início do curso (emec.mec.gov.br)

São oito cursos criados entre 1950 e 2000 (cinquenta anos) e três de 2000 em diante. A maioria foi fundada numa época de grande desenvolvimento dos meios de comunicação social no Brasil e da própria formação em jornalismo. Em relação ao processo de interiorização dos cursos de jornalismo, apenas três (UFMA-Imperatriz, UFCA - Juazeiro do Norte e UFRB - Barreiras) estão fora das capitais e dos grandes centros urbanos e surgiram no momento de digitalização das redações jornalísticas. São cidades de porte médio (até 500 mil habitantes) e de representatividades nas suas regiões de abrangência. Dentro do processo de expansão dos cursos de jornalismo, entre 1990 e 2010, o número de cursos universitários da área no Brasil foi quintuplicado. Esse crescimento resultou de políticas para expandir a educação superior no país, caracterizadas pelo estímulo à atividade de entidades privadas, que atualmente oferecem $81 \%$ de todos os cursos na área e $90 \%$ das vagas. Na região Nordeste, nesse mesmo período, houve crescimento de $50 \%$ de novos cursos. Em comparativo com outras regiões brasileiras, o Nordeste está quase empatado com a região Sul no que diz respeito ao crescimento de novos cursos de jornalismo nas duas modalidades, públicos e privados, nos anos 2010.

De acordo com Jack Mick e Samuel Lima (2012), pesquisador da Universidade Federal de Santa Catarina e autor da pesquisa Quem é o jornalista brasileiro: perfil da profissão no país, antes concentrados nas capitais, os cursos de jornalismo promoviam a migração de estudantes em direção a essas cidades e somente minoria regressava aos territórios de origem depois de completar a formação. Devido à acelerada taxa de crescimento da oferta de cursos, é possível que algumas das características demográficas dos graduados tenham afetado a morfologia do campo. A análise dos efeitos da expansão do ensino superior - especialmente na composição do mercado de trabalho e sobre a renda, como também na estrutura dos campos acadêmicos - requer a produção de indicadores mais precisos sobre a evolução do número de graduados e a interpretação diacrônica dos dados.

Tal expansão democratizou o acesso à formação superior na área ao estender a oferta para todas as unidades da federação e, naquelas em que o curso já 
${ }^{3}$ Entre 2000 e 2010, foram criados cursos de jornalismo em cidades como Juazeiro do Norte (CE), Imperatriz (MA) e Barreiras (BA). existia, para mais municípios do interior. A possibilidade de estudar jornalismo ampliou-se em todas as regiões. Nos anos mais recentes, a oferta foi concentrada principalmente no interior. ${ }^{3}$ A interiorização das universidades contribui para distribuição mais abrangente dos graduados no território nacional. Os três cursos com turmas abertas em 2010 nas universidades federais do Nordeste ofereceram, naquele ano, 170 vagas.

\section{O perfil do docente de telejornalismo e a produção laboratorial das universidades federais do Nordeste}

Para fins de compreensão da produção laboratorial, optamos por efetuar, primeiramente, análise do currículo Lattes dos docentes, da experiência profissional e docente e das produções audiovisuais desenvolvidas nas instituições de ensino a fim de verificarmos a relação entre docência e prática do telejornalismo, atentando para a reflexão crítica necessária ao ambiente acadêmico. Salientamos que, apesar de termos levantado dados numéricos, não é nossa pretensão comparar quantitativamente a produção laboratorial de cada um desses professores, mas apenas ter a noção das condições de produção laboratorial e uso das mídias digitais, o que justifica também a escolha dos indicadores quanto ao formato das produções audiovisuais. A pesquisa dos currículos aconteceu durante os dias $10 \mathrm{e}$ 15 de abril de 2017. A observação foi feita por meio de pesquisa pelos nomes dos professores das disciplinas de Telejornalismo e relacionadas na plataforma Lattes (por questões éticas, os nomes dos professores serão omitidos neste artigo), foi respeitada a atualização das informações correspondentes a cada docente pesquisado. Das doze instituições analisadas, obtivemos dados de oito docentes de Telejornalismo.

\begin{tabular}{|l|c|c|}
\hline Instituições & $\mathbf{N}^{\circ}$ & $\%$ \\
\hline Responderam & 6 & 50 \\
\hline Não responderam & 6 & 50 \\
\hline Total & 12 & 100 \\
\hline
\end{tabular}

Tabela 3: Instituições respondentes

\begin{tabular}{|l|c|c|}
\hline Estado & No & $\%$ \\
\hline Alagoas & 0 & 0 \\
\hline Bahia & 2 & 33,3 \\
\hline Ceará & 2 & 33,3 \\
\hline Maranhão & 1 & 16,6 \\
\hline Paraíba & 0 & 0 \\
\hline Piauí & 1 & 16,6 \\
\hline Pernambuco & 0 & 0 \\
\hline Rio Grande do Norte & 0 & 0 \\
\hline Sergipe & 0 & 0 \\
\hline Total & 12 & 100 \\
\hline
\end{tabular}

Tabela 4: Instituições respondentes por estado

\begin{tabular}{|l|c|c|}
\hline Nomenclatura & Instituições & $\%$ \\
\hline Telejornalismo & 4 & 66,6 \\
\hline Oficina de Telejornalismo & 2 & 33,3 \\
\hline Total & 6 & 100 \\
\hline
\end{tabular}

Tabela 5: Nomenclatura das disciplinas específicas equivalentes a Telejornalismo 


\begin{tabular}{|c|c|c|c|}
\hline \multicolumn{4}{|c|}{ TELEJORNALISMO } \\
\hline UF & NOME & EXP. PROFISSIONAL & EXP. DOCENTE \\
\hline \multirow{2}{*}{ UFCA } & A & $\begin{array}{l}\text { Rádio e Telejornalismo. Entre os } \\
\text { anos de } 1994 \text { e } 2006 .\end{array}$ & $\begin{array}{l}\text { Leciona desde } 2000 \text { Jornalismo e } \\
\text { Telejornalismo. Docente na UFCA } \\
\text { desde } 2010 .\end{array}$ \\
\hline & B & $\begin{array}{l}\text { Marketing, Assessoria de } \\
\text { Imprensa e Editoria. Entre } 1987 \\
\text { e } 2001 .\end{array}$ & $\begin{array}{l}\text { Na área do ensino de jornalismo } \\
\text { desde o ano } 2000 \text {. Docente na } \\
\text { UFCA desde } 2017 .\end{array}$ \\
\hline \multirow{2}{*}{ UFC } & $\mathbf{C}$ & Entre 1999 e 2012. & $\begin{array}{l}\text { Desde } 2012 \text { é professor assistente } \\
\text { do curso de jornalismo da } \\
\text { Universidade Federal do Ceará. }\end{array}$ \\
\hline & D & Repórter de 2008 a 2013. & $\begin{array}{l}\text { Atuou como docente entre os anos } \\
\text { de } 2014 \text { e } 2015 \text {. Docente da UFC } \\
\text { desde o ano de } 2015 \text {. }\end{array}$ \\
\hline \multirow{3}{*}{ UFRB } & E & $\begin{array}{l}\text { Telejornalismo e Assessoria de } \\
\text { Comunicação no período entre } \\
1997 \text { e } 2003 .\end{array}$ & $\begin{array}{l}\text { Leciona e pesquisa desde o ano de } \\
\text { 2002. Docente da UFRB desde o } \\
\text { ano de } 2012 \text {. }\end{array}$ \\
\hline & $\mathbf{F}$ & $\begin{array}{l}\text { Entre } 1989 \text { a } 2007, \\
\text { principalmente na área de } \\
\text { Telejornalismo. }\end{array}$ & $\begin{array}{l}\text { Leciona desde } 2008 \text {. Atuando na } \\
\text { UFRB desde o ano de } 2010 .\end{array}$ \\
\hline & $\mathbf{G}$ & Telejornalismo de 1996 a 2003. & $\begin{array}{l}\text { Leciona desde 2003. Na UFRB } \\
\text { desde } 2009 .\end{array}$ \\
\hline UFMA & $\mathbf{H}$ & $\begin{array}{l}\text { Repórter e assessoria de } \\
\text { imprensa entre } 2007 \text { e } 2013 .\end{array}$ & $\begin{array}{l}\text { Leciona desde } 2010 \text {. Professor } \\
\text { de Telejornalismo e Lab. de } \\
\text { Telejornalismo. }\end{array}$ \\
\hline \multirow{2}{*}{ UFPI } & $\mathbf{I}$ & $\begin{array}{l}\text { Produção, reportagem e edição } \\
\text { em TV, assessoria de eventos e } \\
\text { de imprensa de } 2002 \text { a } 2017 \text {. }\end{array}$ & $\begin{array}{l}\text { Leciona Telejornalismo desde } \\
2015 .\end{array}$ \\
\hline & $\mathbf{J}$ & $\begin{array}{l}\text { Experiência em produção, } \\
\text { reportagem, edição, chefia e } \\
\text { direção. }\end{array}$ & Leciona Telejornalismo de 2006. \\
\hline UFBA & $\mathbf{K}$ & $\begin{array}{l}\text { Repórter, editor e diretor de } \\
\text { jornalismo entre } 1980 \text { a } 1990 .\end{array}$ & $\begin{array}{l}\text { Leciona Oficina de Telejornalismo } \\
\text { desde } 1990 .\end{array}$ \\
\hline
\end{tabular}

Quadro 1: Experiência profissional e docente dos professores de Telejornalismo das universidades federais do Nordeste

O instrumento de pesquisa criado pelos autores foi construído a partir de uma preocupação teórico-metodológica concernente ao tipo de perfil dos docentes, incluindo questões como a formação profissional e acadêmica, pois acreditamos que o impacto da experiência em jornalismo incide no desenvolvimento laboratorial e no uso de tecnologias digitais como ferramentas no ensino. Pôde-se verificar na nomenclatura utilizada nas disciplinas que "Telejornalismo" prepondera na escolha das universidades, correspondendo a $66,6 \%$ das instituições pesquisadas; $33,3 \%$ optam pela nomenclatura "Oficina de Telejornalismo".

Verificamos que a maioria dos docentes possui experiência profissional em jornalismo superior a dois anos, tempo mínimo estipulado pelo Instituto Nacional de Estudos e Pesquisas Educacionais (INEP), órgão do MEC responsável pela regulação dos processos de autorização, reconhecimento e renovação de reconhecimento de cursos. Em números absolutos e/ou relativos, o quantitativo de docentes com experiência profissional em sua área de atuação - excluídas as atividades de magistério superior - chega a 100\%. Quanto à experiência no magistério superior, cerca de $80 \%$ dos docentes possuem mais do que cinco anos. Observa-se também o uso do site YouTube para circulação das produções audiovisuais em laboratório, talvez pela facilidade de postagem e atualização de conteúdo, mesmo que ocorra, em média, a cada três ou cinco meses devido à demanda das disciplinas. As redes sociais de compartilhamento de conteúdo podem alterar o modelo de produção e ter efeito nos formatos. Isso acontece com a tecnologia digital e com a distribuição audiovisual, que facilita determinados procedimentos e formas de organizar a produção e difundi-la. $O$ barateamento 
dos custos de produção, captação e finalização, bem como a possibilidade de criar o próprio canal de exibição na web, popularizaram essa prática, inserindo novos realizadores e novas perspectivas (CANNITO, 2010). A seguir, categorizamos o formato das produções audiovisuais universitárias aplicadas ao ensino do telejornalismo na região Nordeste:

\begin{tabular}{|c|c|c|c|c|c|}
\hline UF & $\begin{array}{l}\text { Formato da } \\
\text { produção }\end{array}$ & UF & $\begin{array}{l}\text { Formato da } \\
\text { produção }\end{array}$ & UF & $\begin{array}{l}\text { Formato da } \\
\text { produção }\end{array}$ \\
\hline UFAL & $\begin{array}{l}\text { - Grande } \\
\text { reportagem. } \\
\text { - Programa de } \\
\text { entrevistas. }\end{array}$ & $\begin{array}{l}\text { UFMA } \\
\text { Imperatriz }\end{array}$ & $\begin{array}{l}\text { - Boletim. } \\
\text { - Telejornal. } \\
\text { - Programa de } \\
\text { entrevistas. } \\
\text { - Grande } \\
\text { reportagem. } \\
\text { - Programa } \\
\text { especial. } \\
\text { - Documentários. }\end{array}$ & UFPI & $\begin{array}{l}\text { - Boletins. } \\
\text { - Grande } \\
\text { reportagem. } \\
\text { - Programa de } \\
\text { entrevistas. } \\
\text { - Programa de } \\
\text { documentário. }\end{array}$ \\
\hline UFBA & $\begin{array}{l}\text { - Boletim. } \\
\text { - Programa de } \\
\text { entrevistas. } \\
\text { - Grande } \\
\text { reportagem. } \\
\text { - Documentários. }\end{array}$ & $\begin{array}{l}\text { UFMA } \\
\text { São Luís }\end{array}$ & $\begin{array}{l}\text { - Boletim. } \\
\text { - Programa de } \\
\text { entrevistas. } \\
\text { - Grande } \\
\text { reportagem. } \\
\text { - Documentários. }\end{array}$ & UFRB & $\begin{array}{l}\text { - Boletins. } \\
\text { - Programa de } \\
\text { entrevistas. } \\
\text { - Programa } \\
\text { especial. }\end{array}$ \\
\hline UFC & $\begin{array}{l}\text { - Boletim. } \\
\text { - Programa de } \\
\text { entrevistas. } \\
\text { - Documentários. }\end{array}$ & UFPB & $\begin{array}{l}\text { - Boletim. } \\
\text { - Telejornal. } \\
\text { - Programa de } \\
\text { entrevistas. } \\
\text { - Grande } \\
\text { reportagem. } \\
\text { - Programa } \\
\text { especial. } \\
\text { - Documentário. } \\
\end{array}$ & UFRN & $\begin{array}{l}\text { - Boletins. } \\
\text { - Grande } \\
\text { reportagem. } \\
\text { - Coluna de } \\
\text { política. } \\
\text { - Programa de } \\
\text { entrevistas. }\end{array}$ \\
\hline UFCA & $\begin{array}{l}\text { - Boletim. } \\
\text { - Telejornal. } \\
\text { - Programa de } \\
\text { entrevistas. } \\
\text { - Grande } \\
\text { reportagem. } \\
\text { - Documentários. }\end{array}$ & UFPE & $\begin{array}{l}\text { - Boletins. } \\
\text { - Programa de } \\
\text { entrevistas. } \\
\text { - Programa de } \\
\text { debates. }\end{array}$ & UFS & $\begin{array}{l}\text { - Programa de } \\
\text { entrevistas. } \\
\text { - Programa } \\
\text { especial. }\end{array}$ \\
\hline
\end{tabular}

Quadro 2: Formato das produções audiovisuais jornalísticas

Os formatos das produções laboratoriais das universidades são contabilizados da seguinte maneira: programa de entrevista (12), boletim (10), grande reportagem (8), documentário (7), programa especial (4), telejornal (3) e coluna política (1). A maioria estabelece relações com as disciplinas de Telejornalismo com formatos pertinentes ao universo on-line, assumindo assim mediação digital da relação professor-aluno no contexto do ensino de jornalismo e se tornando ferramenta pedagógica para o ensino das competências necessárias ao ensino de um novo perfil de jornalista de TV.

\section{Considerações finais}

Com a popularização da internet e sua utilização como um dos principais meios informativos para estudantes universitários, também se faz necessário o 
desenvolvimento de linguagens para essas novas mídias. Os jornais universitários podem ser um espaço também para essa finalidade. Diferentemente do telejornal, exibido diariamente nas emissoras comerciais ou no mercado profissional, o telejornal universitário pode ser um espaço aberto ao treinamento e à experimentação de novas propostas produtivas (BASSANI et al., 2013).

O ensino de jornalismo deve ser teórico, prático e, principalmente, inovador, preparando o estudante para lidar com ferramentas que possibilitam essa inovação tecnológica. As práticas laboratoriais revelaram três formatos mais comuns nas produções universitárias: entrevistas, boletins e grandes reportagens, ou seja, visível adequação do ensino do telejornalismo ao modo de consumo audiovisual no ambiente digital. As entrevistas possuem enquadramentos mais fechados, em plano médio e primeiro plano, como no caso dos boletins e stand-ups (passagens gravadas) com notícias em curto espaço de tempo.

O formato telejornal, modelo linear e tradicional no ensino do telejornalismo, não se mostrou muito comum nas práticas laboratoriais. Apesar de muitas vezes ser produto obrigatório nos cursos de jornalismo brasileiros, os telejornais universitários ainda são de difícil produção nas escolas de comunicação, principalmente nas instituições públicas. Poucos são os cursos que possuem telejornais de exibição regular, uma vez que a produção em telejornalismo costuma ser apenas um espaço para aprendizado teórico, sem regularidade prática. Mais comum ainda é a exibição de reportagens e programas que, embora tenham alunos à frente do processo como repórteres e apresentadores, têm a produção e execução feita por profissionais contratados pela universidade (BRASIL; EMERIM, 2011).

Os resultados também evidenciaram avanço no sentido das estruturas de produção audiovisual, com o surgimento de uma narrativa mais interativa em redes sociais de compartilhamento de conteúdo digital, tornando-se possível a observação de uma nova interface do ensino (interativo-tecnológica), especialmente na produção de narrativas audiovisuais jornalísticas para o ciberespaço, pois a crescente digitalização dos produtos e dos processos midiáticos provoca mudanças significativas na produção. Essas são apenas algumas das questões levantadas na pesquisa preliminar que se impõe neste momento ao processo de ensino do telejornalismo em tempos de convergência.

\section{Referências}

ANTONIOLI, M. E. Ensino de jornalismo e legislação educacional. 2. ed. São Paulo: L'Editora, 2014.

BASSANI, R. et al. TJ UFSC, o telejornal diário da Universidade Federal de Santa Catarina. In: CONGRESSO DE CIÊNCIAS DA COMUNICAÇÃO NA REGIÃO SUL, 14., 2013, Santa Cruz do Sul. Anais... São Paulo: Intercom, 2013. p. 1-8. Disponível em: <http://bit.ly/2ysC6ps>. Acesso em: 16 out. 2017.

BECKER, B. Telejornalismo e media literacy. In: SOSTER, D.; TONUS, M. Jornalismolaboratório: televisão. Santa Cruz do Sul: Unisc, 2015. v. 1, p. 39-60.

BRASIL. Decreto-Lei no 5.480, de 13 de maio de 1943. Institue o curso de jornalismo no sistema de ensino superior do país, e dá outras providências. Diário Oficial da União, Rio de Janeiro, 20 maio 1943. Seção 1, p. 7745. Disponível em: <http://bit. ly/2lhbz9W>. Acesso em: 25 out. 2017.

BRASIL. Decreto no 22.245, de 6 de dezembro de 1946. Dá organização ao Curso de Jornalismo. Diário Oficial da União, Rio de Janeiro, 9 dez. 1946. Seção 1, p. 0. Disponível em: <http://bit.ly/2zEMoQO>. Acesso em: 25 out. 2017. 
BRASIL. Decreto no 23.087, de 19 de maio de 1947. Autoriza o funcionamento do curso de jornalismo da Faculdade de Filosofia, Ciências e Letras de São Bento, da Universidade Católica de São Paulo. Diário Oficial da União, Rio de Janeiro, 23 maio 1947. Seção 1, p. 7003. Disponível em: <http://bit.ly/2y4LpgM>. Acesso em: 25 out. 2017.

BRASIL. Decreto no 24.719, de 29 de março de 1948. Altera o Decreto no 22.245, de 6 de dezembro de 1946, que deu organização ao Curso de Jornalismo. Diário Oficial da União, Rio de Janeiro, 31 mar. 1948. Seção 1, p. 5123. Disponível em: <http://bit.ly/2gINO9q>. Acesso em: 25 out. 2017.

BRASIL. Decreto no 26.493, de 19 de março de 1949. Reorganiza o Curso de Jornalismo. Diário Oficial da União, Rio de Janeiro, 22 mar. 1949. Seção 1, p. 4142. Disponível em: <http://bit.ly/2yRp0CA>. Acesso em: 25 out. 2017.

BRASIL. Decreto no 28.923, de 10 de dezembro de 1950. Reestrutura o Curso de jornalismo da Faculdade de Nacional de Filosofia da Universidade do Brasil. Diário Oficial da União, Rio de Janeiro, 4 dez. 1950. Seção 1, p. 17350. Disponível em: <http://bit.ly/2iyc6Dv>. Acesso em: 25 out. 2017.

BRASIL. Ministério da Educação. Parecer CNE/CES no 39, de 20 de fevereiro de 2013. Diretrizes curriculares nacionais para o curso de graduação em Jornalismo. Diário Oficial da União, Poder Executivo, Brasília, DF, 12 set. 2013a. Seção 1, p. 10. Disponível em: <http://bit.ly/2xKnUsX>. Acesso em: 16 out. 2017.

BRASIL. Ministério da Educação. Resolução CNE/CES no 1, de 27 de setembro de 2013. Institui as Diretrizes Curriculares Nacionais para o curso de graduação em Jornalismo, bacharelado, e dá outras providências. Diário Oficial da União, Brasília, DF, 1ㅇo out. 2013b. Seção 1, p. 26. Disponível em: <http://bit.ly/2y6D4UJ>. Acesso em: 25 out. 2017.

BRASIL, A. C. Telejornalismo imaginário. Florianópolis: Insular, 2012.

BRASIL, A. C.; EMERIM, C. Por um modelo de análise para os telejornais universitários. In: SEMINÁRIO INTERNACIONAL ANÁLISE DE TELEJORNALISMO: DESAFIOS TEÓRICO-METODOLÓGICOS, 1., 2011, Salvador. Anais... Salvador: Grupo de Pesquisa Análise de Telejornalismo, 2011. p. 1-16. Disponível em: <http://bit. ly/2gIXOw4>. Acesso em: 16 out. 2017.

CANNITO, N. A televisão digital: interatividade, convergência e novos modelos de negócios. São Paulo: Summus, 2010.

CLAYTON, E. The golden thread, the story of writing. London: Atlantic Books, 2013.

DIAS, L. C.; DALLA COSTA, R. M. C. O ensino de Jornalismo no Paraná: dicotomia entre teoria e prática e o currículo que está por vir. In: CONGRESSO DE CIÊNCIAS DA COMUNICAÇÃO NA REGIÃO SUL, 16., 2015, Joinville. Anais... São Paulo: Intercom, 2015. p. 1-14. Disponível em: <http://bit.ly/2ii45Cn>. Acesso em: 16 out. 2017.

LIBÂNEO, J. C. Pedagogia e pedagogos, para quê? 3. ed. São Paulo: Cortez, 2000.

LOPES, D. F. Jornal laboratório: do exercício escolar ao compromisso com o público leitor. São Paulo: Summus, 1989.

MICK, J.; LIMA, S. Perfil do jornalista brasileiro: características demográficas, políticas e do trabalho jornalístico em 2012. Florianópolis: Insular, 2012. 